\title{
Processo investigativo sobre práticas pedagógicas para inserção da dimensão ambiental na formação de professores de biologia
}

Maria Inêz Oliveira Araújo'

Nelio Bizzo ${ }^{2}$

\section{Resumo}

Este artigo tem por objetivo apresentar os caminhos percorridos para evidenciar, nas práticas pedagógicas dos professores da USP, indícios que permitam vislumbrar a inserção da dimensão ambiental nos currículos de formação de professores de Biologia. A coleta de dados foi realizada em dois momentos: o primeiro com a seleção das disciplinas, por meio da análise de ementas e programas, e o segundo mediante a análise dos depoimentos dos professores. As concepções e práticas dos professores foram verificadas através de entrevistas. Foi possível evidenciar, nas práticas pedagógicas, elementos que permitiam a inserção da dimensão ambiental nos currículos. Sobre ambiente e sustentabilidade, foram identificados: educação para gestão, para conservação e para emancipação. É prudente, ao tratar da dimensão ambiental, que seja considerada a forma como o conhecimento é adquirido e sua importância para a saúde da comunidade.

Palavras-chave: formação de professores, metodologia, dimensão ambiental.

\footnotetext{
1 Doutora em Educação; Professora do Departamento de Educação e da Pós-graduação em Educação da Universidade Federal de Sergipe. E-mail: inez@ufs.br

2 Doutor em Educação; Professor Titular da Daculdade de Educação da Universidade de São Paulo (USP). E-mail: bizzo@usp.br
} 


\section{Investigative process on educational practices to integration in environmental dimension biology teacher training}

\author{
Proceso de investigación sobre \\ prácticas para la integración educativa \\ de preocupaciones ambientales en \\ biología formación docente
}

\begin{abstract}
The article aims to present the paths taken to highlight the pedagogical practices of teachers from USP,evidences indications leading to envision the insertion of the environmental dimension in the curriculum Biology teacher training. Data were collected in two stages; the first with the selection of subjects through menus analysis and programs, and the second, by analyzing the testimonies of teachers. The conceptions and practices of teachers were verified through interviews. Could be reflected in teaching practices, elements that allowed the inclusion of the environmental dimension in the curriculum. On environment and sustainability were identified: education for management, conservation and emancipation. It is prudent to address the environmental dimension, to be considered how knowledge is acquired and its importance to the health of the community.
\end{abstract}

Keywords: teacher training, methodology, environmental dimension.

\section{Resumen}

El artículo tiene como objetivo presentar los caminos tomados para poner de relieve las prácticas pedagógicas de los profesores de la USP, indicios que permiten prever la inserción de la dimensión ambiental en los currículos de formación del profesorado de Biología. La recolección de datos se llevó a cabo en dos etapas: la primera con la selección de las disciplinas, a través de análisis de programas y contenidos, y la segunda, mediante análisis de los testimonios de los profesores. Las concepciones y prácticas de los docentes fueron verificadas a través de entrevistas. Fue posible distinguir en las prácticas pedagógicas, elementos que permitian la inclusión de la dimensión ambiental en los currículos. Acercar del medio ambiente y la sostenibilidad, fueron identificados: educación para la gestión, conservación y emancipación. Al abordar la dimensión ambiental es prudente que se considere cómo la forma como se adquiere el conocimiento y su importancia para la salud de la comunidad.

Palabras clave: formación del profesorado, metodología, dimensión ambiental. 


\section{Introdução}

A educação ambiental, como processo educativo, tem como principal finalidade inserir a dimensão ambiental no cotidiano das pessoas. Espera-se que ela proporcione ao indivíduo o conhecimento do ambiente complexo, dando-Ihe ferramentas que permitam desenvolver valores e atitudes para agir positivamente no atual contexto de sociedade, em busca da sustentabilidade socioambiental. A implementação da referida educação constitui-se em um processo complexo, sobretudo quando se almeja enfocá-la em toda sua dimensão: ecológica, social, política, tecnológica, cultural e econômica.

A educação sob esse paradigma - ambientalista - torna-se um importante processo na aquisição e construção do conhecimento válido, capaz de preparar o cidadão para tomar decisões comprometidas com o contexto no qual está inserido, visando à construção de uma mentalidade ambiental atenta aos problemas e questões ecológicas e sociais, na medida em que desenvolve a consciência crítica.

De acordo com Paulo Freire (1979), para se alcançar o desenvolvimento dessa consciência, o indivíduo deve: (1) estimular $o$ anseio de profundidade na análise de problemas, reconhecendo que a realidade é mutável; (2) procurar verificar e testar as descobertas e, ao se deparar com um fato novo, fazer o possível para livrar-se dos preconceitos e não repelir o velho por ser velho, nem aceitar o novo pelo novo, mas aceitá-los na medida em que são válidos; (3) repelir posições contempladoras, não transferindo as responsabilidades, nem a autoridade, mas aceitando a delegação das mesmas; por fim, deve indagar, cuidando para sempre manter o diálogo, como cenário propício para a construção do conhecimento.

Dessa forma, para o desenvolvimento da consciência crítica na perspectiva da educação ambiental, faz-se mister a adoção de práticas que desencadeiam no indivíduo o sentimento de pertença e corresponsabilidade com o meio onde está inserido, importante para a formação ambiental do cidadão.

De acordo com Diegues (2001), o estudo dos impactos da ação humana sobre o ambiente localiza-se na interface entre as diversas ciências naturais e sociais, demandando a contribuição e a ação orgânica das diversas disciplinas, ultrapassando os limites da multidisciplinaridade para alcançar a interdisciplinaridade, acrescentando, ao que postula o autor, práticas capazes de promover a consciência crítica, que devem ao mesmo tempo ter suas bases epistemológicas na interdisciplinaridade e na contextualização dos conteúdos.

A inserção da dimensão ambiental, tanto na perspectiva de gestão ambiental, que busca gerir os bens ambientais, quanto na perspectiva emancipatória, que busca a liberdade e propõe a transformação social, tem, no processo educativo e no conhecimento, as ferramentas para a implementação dessa nova ordem educacional. Nessa direção, o conhecimento do ambiente complexo permite a compreensão da realidade, contribuindo para o desenvolvimento da consciência ambiental.

De acordo com Freire (1979), o homem é consciente, na medida em que conhece e tende a se comprometer com a própria realidade. Acredita-se que é através do conhecimento que o indivíduo consciente muda sua forma de se relacionar com o meio, de maneira a conservar os bens naturais para as gerações futuras e a transformar os construtos ambientais, historicamente elaborados pelo homem, em uma sociedade mais justa.

Verificando a teoria da educação crítica, percebe-se que existe entre ela e a educação ambiental propósitos semelhantes. Segundo Paulo Freire (1980), a educação crítica tem por finalidade desenvolver a conscientização do indivíduo. Para esse autor, na referida educação, os seres humanos são considerados inacabados, exigindo-se que a educação seja uma atividade constante e continuamente refeita pela práxis. $\mathrm{O}$ autor argumenta que:

[...] educação crítica é a 'futuridade' revolucionária. [...] profética [...] portadora de esperança. [...] afirma que os homens são seres que se superam, que vão para frente e olham para o futuro, seres para os quais a imobilidade representa uma ameaça fatal, para os quais ver o passado não deve ser mais que um meio para compreender claramente quem são e o que são, a fim de construir o futuro com mais sabedoria. (FREI$R E, 1980$, p. 81-82, grifo do autor). 
Nesse sentido, no que se refere ao ensino formal, faz-se mister uma nova mentalidade para os cursos de formação de professores. Considerando que o professor é legítimo formador de opiniões, é oportuno ressaltar que, para se compreender as questões ambientais para além de suas dimensões biológicas, químicas e físicas, enquanto questões sociopolíticas, é fundamental, para formação desses professores, que a teoria esteja intrinsecamente articulada com o método de aquisição do conhecimento, fundada na experiência e na reflexão e alinhada à formação ambiental, conferindo-lhes saberes necessários para o desenvolvimento da sua profissão.

A universidade é a instituição preponderante na formação inicial desses profissionais, portanto, é de fundamental importância que assuma posição de vanguarda no que diz respeito à inserção da dimensão ambiental nos currículos dos cursos de licenciatura. Espera-se que os profissionais, formados pela universidade, sejam capazes de trabalhar em grupos multidisciplinares e em ações interdisciplinares, de modo que essas ações sejam interativas e reflexivas, capazes de promover o interesse e a participação dos diferentes agentes da sociedade na construção individual e coletiva do conhecimento.

Partindo-se dessa necessidade, procurou-se verificar meios viáveis, já implementados por disciplinas, independentemente de ter sido tornada explícita a intenção de trabalhar sob a perspectiva da educação ambiental. Portanto, buscou-se nas das disciplinas o sentimento ambientalista e práticas ricas que sinalizassem possíveis inserções da dimensão ambiental nos currículos de disciplinas do curso de formação de professores.

De acordo com Araujo; Araujo; Ramos (2013, p.172), a "(...) universidade tem um papel muito importante na formação de profissionais. Ela precisa incorporar a dimensão ambiental nos seus objetivos, conteúdos, metodologia (...)"

O propósito deste artigo é apresentar os caminhos percorridos para evidenciar, nas práticas pedagógicas de professores da Universidade de São Paulo (USP), indícios que permitam a inserção da dimensão ambiental nos currículos de formação de professores de Biologia.

\section{Percurso metodológico}

No sentido de trilhar um caminho metodológico seguro para a aquisição dessas informações, buscou-se apoio na pesquisa qualitativa, que, de acordo com Minayo (1994), responde a questões particulares e se ocupa de um nível de realidade que não pode ser quantificado, visto que se preocupa com o universo de significados, motivações, aspirações, crenças, valores e atitudes, criando um espaço mais profundo das relações, dos processos e dos fenômenos que não podem ser reduzidos à operacionalização de variáveis. Segundo a autora, "a abordagem qualitativa aprofunda-se no mundo dos significados das ações e relações humanas, um lado não perceptível e não captável em equações, médias e estatísticas" (MINAYO, 1994, p.22).

Segundo essa abordagem, o pesquisador é o principal instrumento de investigação, sendo, inclusive, uma das principais características, uma vez que é por meio da interação com o sujeito, de suas leituras e reflexões que são realizadas a coleta e a significação dos dados.

Assim, o processo de construção do conhecimento, por meio da abordagem qualitativa, aos poucos, perde a objetividade proposta pela relação biunívoca entre realidade e conhecimento e assume a subjetividade de um conhecimento produzido por meio da relação pesquisador, pesquisado e conhecimento. Assim, de acordo com Lüdke (1999 p.37), a metodologia se preocupa muito mais com o percurso que levará o pesquisador à construção do conhecimento do seu objeto de estudo do que com regras que ele deverá seguir.

Nesse sentido, concordo com González Rey, pesquisador dedicado à Psicologia Social, quando, ao refletir acerca da epistemologia da pesquisa qualitativa em Psicologia, afirma que:

[...] a ciência não é só racionalidade, é subjetividade em tudo o que o termo implica, é emoção, individualização, contradição, enfim, é expressão íntegra do fluxo da vida humana, que se realiza através de sujeitos individuais, nos quais sua experiência se concretiza na forma individualizada de sua produção. (GONZÁLEZ REY, 2002, p.28) 
Esse processo de produção do conhecimento é definido pelo autor como epistemologia qualitativa, estando apoiado em três princípios:

a) Oconhecimento é uma produção construtiva-interpretativa - o conhecimento não é a soma de fatos definidos por constatações imediatas do momento empírico. A interpretação é um processo em que o pesquisador integra, reconstrói e apresenta, em construções interpretativas, diversos indicadores obtidos durante a pesquisa, os quais não teriam sentido se fossem tomados de forma isolada, como constatações empíricas. Nessa abordagem, a teoria está presente para instrumentalizar o pesquisador nas suas interpretações.

b) O caráter interativo do processo de produção de conhecimento - enfatiza a relação pesquisador-pesquisado. Sendo uma condição para o desenvolvimento das pesquisas, é uma dimensão essencial do processo de produção do conhecimento. O caráter interativo outorga valor especial aos diálogos que nela se desenvolvem e nos quais os sujeitos se envolvem emocionalmente e comprometem sua reflexão de modo a produzirem informações de grande significado para a pesquisa.

c) A significação da singularidade como nível legitimo da produção do conhecimento - pressupõe a subjetividade dos sujeitos estudados, dando-lhes significado qualitativo. Nesse caso, a singularidade não é sinônimo de individualidade. $O$ conhecimento científico não se legitima pela quantidade dos sujeitos a serem estudados, mas pela qualidade de sua expressão. O número dos sujeitos a serem estudados responde a um critério qualitativo, definido essencialmente pelas necessidades do processo de conhecimento que surgem no curso da pesquisa. (GONZÁLEZ REY, 2002, p. 31-35).

Para definir parâmetros de orientação e avaliação para o percurso da investigação, optou-se por seguir a orientação de Alves-Mazzotti e Gewandsnajder (2000, p.148), paralelamente à construção do referencial teórico, e desenvolver uma pesquisa exploratória. Segundo os autores:

[...] nos estudos qualitativos, a coleta sistemática de dados deve ser precedida por uma imersão do pesquisador no contexto a ser estudado.
Essa face exploratória permite que o pesquisador, sem descer ao detalhamento exigido na pesquisa tradicional, defina pelo menos algumas questões iniciais, bem como os procedimentos adequados à investigação dessas questões.

A primeira iniciativa, para imergir no problema, foi verificar as concepções que alunos dos últimos períodos do curso de licenciatura da Universidade Federal de Sergipe-UFS e da Universidade de São Paulo-USP e alguns professores tinham sobre educação ambiental e dimensão ambiental. Foram escolhidos, então, os alunos dos últimos períodos, por existir grande probabilidade de que esses alunos já possuíssem, em seu repertório, elementos significativos à questão aqui delineada. A segunda iniciativa foi pesquisar as concepções que professores de outra universidade possuíam acerca da educação ambiental.

Essa fase exploratória contou com dois momentos distintos de acesso às informações. $O$ primeiro, a utilização do questionário para verificar as concepções dos alunos acerca das expressões interdisciplinaridade, sustentabilidade, ambiente e educação ambiental. O segundo, mediante entrevista, consistiu na verificação das concepções dos professores e no estudo da forma adequada para a coleta de dados. Foram elaborados dois questionários: o primeiro respondido por alunos da Universidade Federal de Sergipe - UFS, e o segundo, por alunos da Universidade de São Paulo - USP.

O resultado mostrou que, para a pergunta sobre a concepção de ambiente, a maioria dos alunos respondeu utilizando-se da definição de ecossistema. Porém, ao responder as questões que relacionam implicitamente o conceito de ambiente, eles apresentaram a concepção de ambiente antropocêntrico ou biocêntrico. Sobre sustentabilidade, os alunos não apresentaram com muita clareza suas noções e não fizeram relação com o processo educativo ou com a finalidade da educação ambiental. Sobre interdisciplinaridade, a maioria dos estudantes apresentou suas concepções relacionadas à prática pedagógica sob a vertente multidisciplinar.

Ainda com o intuito de conhecer o campo de estudo, utilizando os critérios definidos para seleção da amostra da pesquisa, foram selecionadas disciplinas do Curso de 
Licenciatura em Ciências Biológicas da Universidade Federal de Sergipe - UFS e entrevistados os professores das disciplinas selecionadas. Essas entrevistas tiveram como principal objetivo servir como "pilotos", de maneira a avaliar e definir o tempo necessário para cada entrevista, o espaço entre elas, a elaboração e utilização dos roteiros, a seleção das questões a serem abordadas etc.

De acordo com Alves-Mazzotti e Gewandsnajder (2000), é através da imersão do pesquisador no contexto que ele terá uma visão geral do problema considerado, focalizando assim as questões e identificando informações e outras fontes de dados que lhe permitam melhor conduzir sua pesquisa.

Mediante os resultados dessa fase exploratória, foi possível definir quatro questões importantes: (a) a maneira como os professores estão introduzindo práticas e conceitos que favoreçam a inserção da temática ambiental em suas aulas; (b) como eles percebem a relação dos conteúdos e conceitos com a dimensão ambiental; (c) qual o nível de consciência do entrevistado sobre características de sua disciplina que coincidem com os conceitos básicos da educação ambiental; e (d) como eles explicam a presença desses conceitos na sua prática pedagógica.

As disciplinas foram selecionadas mediante indícios e indicadores presentes nas ementas e nos programas, que sinalizaram o potencial da disciplina para introduzir as questões ambientais. Para González Rey (2002), os indicadores são elementos que adquirem significação graças à interpretação do pesquisador, que, por sua vez, se constrói sobre a base de informação implícita e indireta, pois não determina nenhuma conclusão do pesquisador em relação ao estudado, representa um momento hipotético no processo de produção de informação.

No primeiro momento, o de análise das ementas, tomou-se como referência termos que indicassem os aspectos sociais, ecológicos e econômicos. No segundo momento, referente à análise dos programas, foram tomadas como referência as disciplinas que apresentaram os objetivos orientados e apropriados ao desenvolvimento de uma ética ambiental que vinculasse a conservação da biodiversidade, dos mananciais e bens naturais ao respeito pelas diferenças étnicas, culturais e sociais da espécie humana. De acordo com Leff (2001, p. 93-94), a ética ambiental apresenta "[...] objetivo de preservar os recursos naturais e envolver as comunidades na gestão do ambiente, no direito humano a conservar a própria cultura e tradição, no direito de tecer seu destino a partir de seus valores e da visão de mundo". Por exemplo, a disciplina Ecologia Humana visa "introduzir a problemática do crescimento populacional frente à escassez de recursos". Dessa forma, introduz a discussão sobre o ambiente antropocêntrico, o que pode levar ao estudo das relações ambientais, à construção de saberes e ao desenvolvimento da consciência ambiental.

Nos conteúdos, buscou-se a relação entre os componentes ambientais e os conteúdos científicos, possibilidades para o desenvolvimento de valores éticos e de saberes ambientais. Portanto, verificou-se a vocação para a formação da consciência ambiental, sua relevância no processo de construção de cidadania e/ou compreensão da realidade, a presença de conceitos diretamente relacionados com as questões socioecológicas, e conteúdos teóricos e metodológicos, que favoreçam a formação do professor de Biologia em concordância com o paradigma ambiental. Por exemplo, a disciplina "Coleta e Manutenção de Material Biológico", de formação pedagógica, apresenta a preocupação com os limites éticos do relacionamento entre seres humanos e outros organismos, procura introduzir a preocupação com a manutenção da biodiversidade, com a redução das agressões ao meio e com a postura do profissional diante dessas questões.

Nos procedimentos, procurou-se indícios de métodos que favorecessem a interlocução entre os alunos, alunos-professor(es) e alunos-comunidade, propondo a elaboração do conhecimento multidisciplinar ou/e interdisciplinar em lugar da aquisição simples e passiva. Nessa etapa, com base no referencial teórico, as disciplinas apresentaram as seguintes evidências:

a) Trabalho em grupo - por permitir a interlocução entre os alunos, sinalizando para a interação de opiniões, favorecendo, com isso, um conhecimento multifacetado;

b) Pesquisas - por sinalizar a construção do conhecimento em situação ativa por parte do aluno, seja pesquisa 
de campo ou bibliográfica. Quando se trata de pesquisa de campo, promove-se o contato com a situação concreta de comunidade, ou mesmo com os fatores bióticos e abióticos do ambiente;

c) Excursões - por facilitar o diálogo entre os alunos, o objeto de estudo e o professor;

d) Seminários - por predispor o aluno à elaboração de conhecimento fundamentado em pesquisa, seja ela de campo ou bibliográfica, e à organização das ideias por um pequeno grupo para possibilitar o entendimento dos colegas e, assim, provocar a discussão;

e) Discussões de textos - por promover a interlocução entre os alunos e o professor e estimular o desenvolvimento do senso crítico, da argumentação e da alteridade.

$\mathrm{Na}$ avaliação, procuraram-se evidências não para aferir o conhecimento, mas para dar oportunidade ao aluno de refletir sobre esse conhecimento elaborado/adquirido durante o curso da disciplina - a avaliação de processo.

\section{A Educação Ambiental na Concepção dos Pro- fessores do Curso de Formação de professores de Biologia}

Para verificar as concepções dos professores e suas relações com as práticas desenvolvidas, optou-se por adotar a entrevista semiestruturada. De acordo com Alves-Mazzotti e Gewandsznadjder (2000, p.168), a natureza interativa da entrevista permite tratar de temas complexos que dificilmente poderiam ser investigados adequadamente por meio de questionários, explorando-os em profundidade. Nessa fase, foi possível identificar as experiências significativas, compreender as dificuldades enfrentadas pelos professores universitários, as limitações que o processo de ensino formal apresenta para a implementação de ações que visem à educação ambiental e a sua viabilidade. Desse modo, foi possível compreender as concepções e práticas dos professores que, de algum modo, fossem significativas em relação à inserção da dimensão ambiental e seu efeito na formação do licenciado em Ciências Biológicas.
De acordo com os resultados, foi possível evidenciar elementos que permitem a inserção da dimensão ambiental. Um professor, ao explicar sua metodologia, apresentou um caminho para essa inserção: o estudo do meio. De acordo com esse professor, em uma das atividades desenvolvidas na disciplina, os alunos podem escolher qualquer ambiente para estudar.

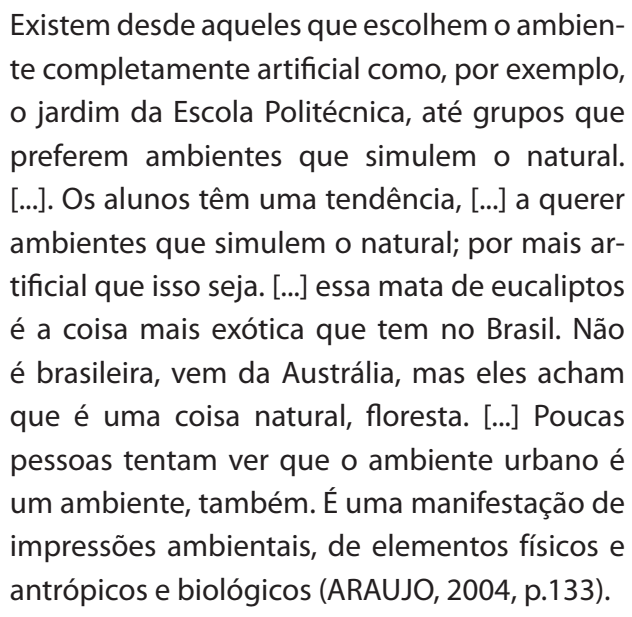

Com os depoimentos, foi possível verificar algumas tendências dessa inserção:

Primeira - a educação para a gestão, que se caracteriza por apresentar uma proposta educativa que visa à sustentabilidade mediante gestão dos recursos naturais, defendendo a preservação ambiental ancorada na visão biocêntrica de ambiente. Como explica um professor ao falar do conteúdo da sua disciplina: “Dentro da relação homem-ambiente, pode-se enfatizar a influência do homem no ambiente ou a influência do ambiente no homem. Muitos dão mais ênfase à influência do ser humano no ambiente; e, em termos mais imediatos, como esse ambiente é alterado, como está modificando a qualidade de vida do ser humano, mas não do ponto de vista evolutivo. A base do curso é este enfoque ambiental (ARAUJO, 2004, p.132).

Dessa forma, reconhece-se a responsabilidade do homem na preservação do ambiente, mas não se reflete sobre a necessidade de uma transformação social, não são manifestas explicitamente as implicações do contexto socioeconômico da sociedade como precursor da 
relação homem-natureza e a necessidade de uma transformação no modelo de sociedade em favor da conservação ambiental.

Segunda - educação para a conservação emerge da visão antropocêntrica do ambiente, geralmente encontrada em campanhas e movimentos sociais. Na escola, manifesta-se através de projetos de investigação ou de pesquisa bibliográfica. Segundo um professor, um ponto importante é trabalhar a questão da sustentabilidade, mediante o exercício de zoneamento ecológico-econômico. Nesse exercício, o aluno planeja a ocupação de um território em função das suas potencialidades, em função dos seus limites, procurando integrar aspectos de fragilidade do ambiente, com as vontades de desenvolvimento econômico do ser humano. Dessa forma, os alunos elegem um problema, definem, junto com a gente, uma metodologia correspondente àquele problema, vão a campo, fazem a pesquisa, fazem entrevista, seja lá qual for o campo, mas coletam dados novos. Não é apenas pesquisa bibliográfica. Eles coletam dados novos, analisam e discutem os resultados (ARAUJO, 2004).

Nessa tendência, os problemas e as questões ambientais servem de pretexto para o ensino, cuja finalidade é conhecer o ambiente. Alguns autores chegam a afirmar que a educação, sob essa perspectiva, é contemplativa e apresenta tênues indícios de transformação social.

A educação para emancipação ou educação crítica caracteriza-se por apresentar uma proposta educativa que visa à sustentabilidade, mediante fortes propósitos de transformação social, pela participação ativa do indivíduo no processo de construção e reconstrução do ambiente próximo. Para essa perspectiva, não foi possível identificar elementos viáveis nos depoimentos do professores. O ambiente é tomado em rede de fenômenos complexos, sendo historicamente construído pelo homem. Essa tendência transcende a prática preservacionista e contemplativa. Para então formar um professor para agir nessa égide educacional, concordo com Araujo (2012) quando argumenta que as finalidades e princípios da abordagem da educação ambiental crítica requerem uma formação fundada na experiência e na reflexão alinhada à formação ambiental.
Outro caminho para inserir a dimensão ambiental diz respeito ao modo como ocorre a aquisição do conhecimento. Algumas disciplinas apresentaram métodos que atendem aos objetivos da educação ambiental, como por exemplo: zoneamento urbano, estudo de caso, pesquisa de levantamento com apresentação de seminários.

Também foi possível identificar procedimentos didáticos que aproximam a concepção de interdisciplinaridade como aquisição do conhecimento mediante pesquisa, em que vários especialistas estariam discutindo o objeto de estudo no mesmo momento e local.

Com a reforma curricular de 1995, foi introduzida, no currículo do Curso de Licenciatura em Ciências Biológicas da USP, em nível estrutural e administrativo, uma nova perspectiva disciplinar: as chamadas disciplinas interdepartamentais. Essas disciplinas abrem espaços favoráveis ao desenvolvimento de práticas interdisciplinares ou multidisciplinares, porém, é sob o pensar docente que as ementas vão ser transformadas em disciplinas e são construídas as identidades de cada uma delas. É por meio das concepções e da visão de mundo dos professores que é construída a identidade disciplinar. Sob essa argumentação é possível compreender por que muitas das modificações curriculares não atendem às expectativas, pois a pessoa que idealiza o currículo tem visão de mundo diferente daquela das pessoas que o executarão (ARAUJO, 2004 p.188).

A interpretação dada às ementas dessas disciplinas, refletidas na forma como os programas foram pensados e executados, mostra que a essência da disciplina está eivada das concepções docentes. Dessa forma, adotaram diferentes maneiras para organizar suas atividades que foram desde aulas com um professor dos departamentos envolvidos até aulas partilhadas por diferentes professores agindo ao mesmo tempo, a começar do planejamento até a execução da aula.

Isso fica claro nas diferentes interpretações e formas que as disciplinas interdepartamentais foram desenvolvidas. A análise dos dados apresentados nas entrevistas aponta três formas de implementação das ementas: 
Na primeira, o programa é desenvolvido por diferentes professores especialistas, cada um abordando o conteúdo do domínio de sua especialidade em aulas separadas. O planejamento é elaborado em conjunto, porém as aulas ficam distribuídas entre eles. Apresenta uma metodologia definida e criativa, tendo como principal preocupação a formação científica do aluno: saber questionar, ver as evidências, elaborar hipóteses e testá-las, chegando a esboçar conclusões.

Na segunda, o programa é desenvolvido sob a coordenação de um professor, com a colaboração permanente de outros. A interação entre os professores ocorre na fase de elaboração do planejamento. Também fazem parte dessas disciplinas professores convidados de outros departamentos e de outras unidades, que colaboram ministrando palestras ou desenvolvendo unidades conceituais alinhadas a uma metodologia adequada. Apresentam metodologia diversificada, contribuindo para instrumentalizar o licenciando para o ensino.

Um dado de grande relevância, que aponta explicitamente para uma perspectiva de inserção da dimensão ambiental, surge com a terceira forma de implementação. Há um entendimento, por partes dos professores, que eles estejam envolvidos em todo o desenvolvimento da disciplina: planejamento, execução e avaliação. Essa forma de implementação vislumbra práticas interativas e integradas de conteúdos e opiniões durante o processo de aquisição do conhecimento, mediante investigação científica, promovendo uma relação horizontal de respeito e de confiança entre os professores e entre alunos e professores. É uma implementação que enfatiza a formação ambiental, calcada na pesquisa sob o enfoque interdisciplinar, e que, de maneira sutil, contribui para a formação pedagógica do licenciando.

Nesse aspecto, considerando os princípios da educação ambiental, os quais recomendam o enfoque interdisciplinar, sem explicitar qual o entendimento que é dado a esse enfoque, é urgente a necessidade de aferir, no meio acadêmico, as diferentes formas e concepções de interdisciplinaridade e sua correlação com a produção de conhecimento. $\mathrm{O}$ entendimento dessa perspectiva de produção do conhecimento pode contribuir para o licenciando planejar atividades didáticas destinadas aos alunos da Educação Básica, apropriadas aos objetivos e condições do contexto onde se desenvolve a educação, assim como atender às necessidades dos alunos e da sociedade.

A interdisciplinaridade, vivenciada pelos entrevistados, insere as questões ambientais na discussão dos temas, mas não transcende a compreensão de integração dos conteúdos para o processo de apropriação ou construção do conhecimento. A educação ambiental requer uma perspectiva metodológica, sob o enfoque interdisciplinar que, à medida que o aluno se apropria do conteúdo, exercita a alteridade, o respeito, a solidariedade, a argumentação e, com isso, desenvolve valores e atitudes éticas em favor da conservação do meio natural e para a defesa dos direitos humanos para todos, irrestritamente.

Assim, o processo de aquisição de conhecimento é imperativo na formação de valores e atitudes éticas profissionais dos licenciandos. A partir desse conhecimento, é possível vislumbrar a transcendência do estágio de sensibilização dos problemas ambientais, comuns nas práticas tradicionais, para a tomada de consciência, capaz de gerar ação. De acordo com Maturana (2001, p. 62), a forma de expressão do conhecimento é verificada por meio de uma conduta adequada, como explica o autor (p. 61), quando se deseja construir o conhecimento de uma pessoa, se faz uma pergunta. Se a pessoa demonstrar, na ação ou no discurso, uma resposta satisfatória para a pergunta, pode-se dizer que essa pessoa apresentou uma conduta adequada e, portanto, tem conhecimento sobre o tema. Concordo com Maturana quando afirma que o problema está em identificar a conduta adequada ou mostrar de que modo ela pode se manifestar. Esse é um dado importante para a educação ambiental, porque a conduta adequada não se resume a respostas diretas, nem se reduz a provas isoladas, mas pode ser alcançada de uma avaliação contínua. A educação ambiental, cuja finalidade da aquisição do conhecimento é a sustentabilidade, envolvendo a conservação do ambiente natural e a equidade social, requer que as informações sejam transformadas em ação, que o conhecimento não seja reduzido ao acúmulo de conceitos, mas transformado em ferramenta para o indivíduo agir em sua sociedade. 


\section{Práticas Desenvolvidas no Curso de Formação de Professores de Biologia}

Algumas práticas descritas nas entrevistas vislumbram a construção do conhecimento ensejado pela educação ambiental, como o 'zoneamento ecológico econômico', realizado na disciplina Ecologia Humana, e o 'estudo do meio', realizado na disciplina Fauna, Flora e Ambiente.

O zoneamento ecológico é uma atividade em que os alunos planejam a ocupação de um território em função das suas potencialidades e dos seus limites, procurando integrar aspectos de fragilidade do ambiente com as vontades de desenvolvimento econômico do ser humano, enquanto o estudo do meio proporciona aos alunos refletirem sobre os problemas ou aprofundarem o conhecimento sobre uma determinada localidade. Com essas atividades, o aluno é colocado em contato direto com o problema, busca solução e, nesse movimento, apropria-se do conhecimento que contribui para sua formação profissional, incrementando, ao mesmo tempo, a formação ambiental.

Outra atividade que vislumbra o envolvimento do aluno com o objeto que se quer conhecer é o estudo de caso. Não é de se esperar que o por meio desse método realizado no curso de graduação atenda as exigências que o caracteriza como tipo de pesquisa. Porém, é possível que, dessa forma, o aluno adquira informações significativas para sua formação pessoal e profissional. Com o estudo de caso, os alunos elaboram conhecimento ao mesmo tempo em que interagem com aspectos sociais, políticos, econômicos e sua influência no aspecto ecológico do objeto em estudo. Os trabalhos de campo, geralmente realizados em meio concreto, permitem aos alunos aproximar o conteúdo de sala de aula aos fatos que se apresentam no meio.

Apesar de o estudo de caso ser uma atividade eficiente na aquisição do conhecimento, ele pode deixar a desejar no que diz respeito à interação e integração dos conteúdos tratados pelos outros grupos. Nesse sentido, a fim de aproximar os vários temas estudados pela classe e minimizar o distanciamento das apresentações orais, os tradicionais seminários podem ser substituídos por uma atividade integradora dos conteúdos, de construção coletiva, que permita o envolvimento desses alunos em torno da construção de um tema maior, por exemplo, a construção de um mapa conceitual.

De acordo com Costamagna (2001), mapa conceitual constitui um recurso de avaliação, capaz de expressar o grau de conhecimento sobre um determinado tema, possível de ser aperfeiçoado mediante o necessário intercâmbio entre o professor e os alunos. Além do aprofundamento dos conteúdos, também serve para explorar explicitamente relações entre proposições e conceitos, evidenciar semelhanças e diferenças significativas e aproximar inconsistências reais ou aparentes.

Com isso, não houve a pretensão de eleger a boa ou a má alternativa metodológica, mas buscar, junto às concepções dos professores, a clareza do significado dos conteúdos tratados em classe para a sociedade em que se insere e a maneira de transformá-los em conhecimento. A atividade didática, nessa abordagem de educação, não se reduz no melhor meio de transmitir ou ensinar conceitos a qualquer pessoa, mas na ferramenta necessária para auxiliar e orientar a construção do conhecimento.

\section{Considerações finais}

A educação ambiental exige que o planejamento pedagógico contemple, explicitamente, a relação ser humano social e meio natural, e que, a partir da aquisição de conceitos científicos e tecnológicos, promova no indivíduo o desenvolvimento de novas atitudes em função da sustentabilidade ambiental.

A dimensão ambiental no processo educativo é algo que transcende o simples debate ou abordagem de temas referentes às questões ambientais no processo educativo. Trata-se de uma "expressão" que requer que o processo de aquisição do conhecimento desencadeie no indivíduo a tomada de consciência sobre a complexidade que envolve os problemas ambientais, o papel do conhecimento na conduta individual e no destino do ambiente. É necessário promover o vínculo entre as questões ambientais e o agir do ser humano, por meio de posturas 
científicas mais integradoras que utilizem explicações causais, mas que também busquem o significado dessas explicações para o contexto social e cultural.

Devido à amplitude do atual conceito de ambiente, envolvendo, além dos aspectos ecológicos, a esfera social, tecnológica, política, econômica, cultural, religiosa, e por considerar os conteúdos discutidos em sala de aula como componentes do ambiente, é prudente que, quando se trata da dimensão ambiental nos conteúdos, seja considerada a forma como o conhecimento é adquirido e sua importância para a saúde da comunidade próxima e distante.

Nesse contexto, um dado de relevância para a mudança de mentalidade é a preocupação com as questões ambientais. Não há explicitamente a pretensão de inserir a dimensão ambiental nos currículos, mas o movimento entre as inovações didáticas e as necessidades de preservação ambiental tem contribuído para introduzir, no meio acadêmico, os conceitos de interdisciplinaridade e sustentabilidade.

Conhecer as concepções dos professores foi o ponto de partida para chegar às propostas metodológicas viáveis para a inserção da dimensão ambiental no currículo. Os professores apresentam concepções variadas de interdisciplinaridade que vão desde uma simples integração dos conteúdos disciplinares, considerada por Japiassú como multidisciplinar, até como instrumental de pesquisa para a aquisição do conhecimento complexo, semeIhante ao que sugere Piaget.

Assim, pelo que foi apresentado na pesquisa, haverá avanços nítidos no campo da educação ambiental, quando mais professores se sentirem estimulados a participar de disciplinas interdepartamentais, promovendo a interação entre seus pares e entre os conteúdos especializados e se dispuserem a inserir a dimensão ambiental nos programas disciplinares. É urgente a mudança de mentalidade e, para tanto, é necessária a explicitação do enfoque ambiental nas ementas e nos programas.

Considerando esses argumentos, é de se esperar que não se chegue a uma conclusão definitiva e geral, visto que para cada realidade existe um caminho a percorrer. Porém, os pontos discutidos ao longo do trabalho devem contribuir para uma discussão mais ampla sobre os caminhos e percursos da implementação da educação ambiental no ensino formal. No entanto, é necessário que estejamos atentos ao contexto e às condições, assim como aos objetivos curriculares nos quais será inserida a dimensão ambiental. Por fim, práticas existentes, em especial as encontradas nos depoimentos dos professores, vislumbram caminhos viáveis para inserção da dimensão ambiental nos currículos de formação de professores de Biologia.

\section{Referências bibliográficas}

ALVES-MAZZOTTI, A. J. e GEWANDSZNAJDER, F. O Método nas Ciências Naturais e Sociais: pesquisa quantitativa e qualitativa. $2^{a}$ ed. São Paulo: Pioneira, 1999.

ARAUJO, M.I.O. A dimensão ambiental no currículo do curso de formação de professores de Biologia. Programa de Pós-Graduação da Faculdade de Educação da USP. Tese de doutoramento, São Paulo, 2004.

ARAUJO, Maria Inêz Oliveira. Educação ambiental para professores. IN: ARAUJO, Maria Inês Oliveira; SOARES, Maria José Nascimento. Educação ambiental: o construto de práticas pedagógicas. São Cristóvão : EDUFS, 2012.

ARAUJO, Maria Inêz Oliveira; ARAUJO Aneide Oliveira; RAMOS, Maria Conceição Pereira. $O$ uso do filme na perspectiva da construção da cidadania no contexto do ensino superior. IN: GUIMARÃES, Leandro Belinaso; GUIDO, Lúcia Estevino; SCARELI, Giovana. Cinema, Educação e Ambiente. Uberlândia: EDUFU, 2013.

DIEGUES, A. C. Ecologia Humana e Planejamento em Áreas Costeiras. $2^{\mathrm{a}}$ ed. São Paulo: Núcleo de Apoio à Pesquisa sobre Populações Humanas, USP, 2001.

FREIRE, Paulo. Conscientização: teoria e prática de libertação: uma introdução ao pensamento de Paulo Freire. Tradução de Kátia de Mello e Silva. 3a ed. São Paulo: Moraes, 1980.

FREIRE, Paulo. Educação e mudança. Tradução de Moacir Gadotti e Lílian Lopes Martin. 21º ed. Rio de Janeiro: Paz e Terra, 1979.

GONZÁLEZ REY, Fernando Luis. Pesquisa Qualitativa em Psicologia: caminhos e desafios. Tradução de Marcel A F. Silva, São Paulo: Pioneira Thomsom Learning, 2002.

LEFF, E. Saber ambiental: sustentabilidade, racionalidade, complexidade, poder. Tradução de Lúcia Mathilde Enddlich Orth. Petrópolis: Vozes, 2001. 
LÜDKE, M. Aprendendo o caminho da pesquisa. In: FAZENDA, I. Novos enfoques da pesquisa educacional. 3 ed. São Paulo: Cortez, 1999. p. 35-50

MINAYO, M. C. de S. Ciência, técnica e arte: o desafio da pesquisa social. In: Pesquisa social: teoria, método e criatividade. MINAYO, M. C. de S. (Org). Petrópolis: Vozes, 1994.

Recebido em 10 de junho de 2015.

Aceito em 08 de julho de 2015. 